\title{
The Norwegian version of the QOLIBRI - a study of metric properties based on a 12 month follow-up of persons with traumatic brain injury
}

Helene Lundgaard Soberg ${ }^{1 *}$, Cecilie Roe ${ }^{1}$, Cathrine Brunborg ${ }^{2}$, Nicole von Steinbüchel ${ }^{3}$ and Nada Andelic ${ }^{1}$

\begin{abstract}
Background: Consequences after Traumatic brain injury (TBI) affect the injured person's self-image and quality of life. The purpose was to assess the health related quality of life (HRQoL) at 12 months after a TBI in patients admitted to regional trauma centres, and to evaluate the metric properties of the Norwegian version of the Quality of Life After Brain Injury (QOLIBRI) questionnaire.
\end{abstract}

Methods: Two hundred four patients with TBI of all severities were included. HRQoL at 12 months post-injury was measured by the QOLIBRI. It has a total scale and 6 subscales (satisfied with Cognition, Self, Daily Life and Autonomy and Social Relationships, and bothered by Emotions and Physical Problems). Demographic and injury related data were registered. Disability was registered by Glasgow Outcome Scale Extended (GOSE) and Rivermead Post-Concussion Questionnaire, and mental health by Hospital Anxiety and Depression Scale. Descriptive statistics, internal consistency by Cronbach's alpha and Corrected Item-Total Correlations were calculated. Rasch analysis, Principal Component Analysis (PCA) and Structural Equation Modelling (SEM) were applied.

Results: Mean age was 37.6 (SD 15.4) years; 72\% were men, and 41\% had higher education. Over 60\% were severely injured. Mean Glasgow Coma Scale score was 9.3 (SD 4.5). According to the GOSE 5.9\% had severe disability, $45.5 \%$ had moderate disability, and $48.5 \%$ had good recovery at 12 months post-injury. The QOLIBRI scales had a high internal consistency $(a=0.75-0.96)$, and only Physical Problems had an $a<0.85$. In the Rasch analysis all subscales and their items fit the Rasch model, except for the depression item in the Emotion subscale. PCA and SEM analyses supported a six-factor structure in a second-order latent model. The QOLIBRI supports an underlying unidimensional HRQoL model. The SEM model fit statistics of the second-order model indicated a moderate fit to the observed data $\left(C F I=0.86, T L I=0.85, \operatorname{RMSEA}=0.076, \mathrm{SRMR}=0.061, \mathrm{X}^{2}=1315.76, \mathrm{df}=623\right.$, $p$-value $<0.001)$.

Conclusion: The Norwegian QOLIBRI has favourable psychometric properties, but there were some weaknesses related to its measurement properties of the total score when tested on a TBI population where many had severe TBI, and many had good recovery.

Keywords: Disability, Metric properties, Outcome measure, Quality of life, Traumatic brain injury, QOLIBRI, GOSE

\footnotetext{
* Correspondence: h.l.soberg@medisin.uio.no

${ }^{1}$ Department of Physical Medicine and Rehabilitation, Oslo University

Hospital, Postbox 4950, Nydalen 0424 Oslo, Norway

Full list of author information is available at the end of the article
} 


\section{Background}

Traumatic brain injury (TBI) can have physical, cognitive, emotional and behavioural consequences, and the resulting impairments can give activity limitations and participation restrictions which subsequently representing lifelong disabilities [1-9]. These disabilities affect the injured person's self-image and their quality of life $[4,10,11]$. Functional recovery after TBI largely varies according to its severity [12-15].

Activity, social integration and participation are key outcomes and core domains of rehabilitation research and are also considered essential for an individual's quality of life (QoL) [16, 17]. Generic QoL concepts incorporate a person's subjective sense of well-being in terms of their physical, psychological, and social functioning and support, as well as their coping strategies, self-efficacy, and self-conception [18, 19]. The concept of health-related quality of life (HRQoL) focuses on the specific impact of health on an individual's subjective functioning and wellbeing $[11,20]$. HRQoL can be operationalized through assessments of physical, psychological (emotional and cognitive), social and daily life domains, and these assessments are predominantly self-reported [10].

Two types of measures are associated with the concept of HRQoL. Generic instruments can be used to compare HRQoL across disease conditions, but they may not capture the particular problems typically experienced by those with a specific condition, e.g., TBI. In contrast, diseasespecific HRQoL instruments are targeted to a specific health condition and should only contain items that are relevant to a specific disease; these questionnaires can therefore be particularly relevant in clinical settings. Given this background, the Quality of Life after Brain Injury questionnaire (QOLIBRI), a disease-specific self-report measure assessing the HRQoL of people after TBI, was developed in an international multicentre study $[11,21,22]$. The QOLIBRI assesses six dimensions of HRQoL according to six subscales (satisfaction with Cognition, Self, Daily Life and Autonomy, and Social Relationships and feeling bothered by Emotions and Physical Problems). The QOLIBRI is applicable to people with TBI of all severities and at all time points after the injury [22]. However, to date, no studies have measured the HRQoL of people with TBI of all severities using the QOLIBRI at a specific time point after their injury.

The metric properties of the QOLIBRI have previously been investigated using classical and modern test theory in an international sample of 795 persons who had experienced a TBI $[11,21]$. In that study, the individual scales showed good internal consistency, with Cronbach's alphas ranging from 0.75 for Physical Problems to 0.89 for Cognition and Self and 0.95 for the total score [11]; this good internal consistency was maintained in a subsample of patients with lower cognitive performance. Furthermore,
Rasch analyses of each subscale and of the total score confirmed that the items had a satisfactory fit with their respective subscales. However, the Social Relationships and Physical Problems subscales showed a poor fit with a unidimensional model and only moderately supported the unidimensionality of the total scale [11].

The QOLIBRI was originally translated into Norwegian in 2008 in accordance with recommended procedures [23]. However, the metric properties of the Norwegian version of the QOLIBRI have not yet been published. Additionally, its properties have not been tested in people with TBI of all severities at 12 months post-injury, when a rather stable life situation either at home or in a supported living environment can be expected [24].

The aim of this study was to assess HRQoL 12 months post-injury and to evaluate the metric properties of the Norwegian version of the QOLIBRI and its subscales in patients across the spectrum of TBI severity. In particular, we aimed to test the dimensionality of the scale and its ability to capture the extent of patients' problems. We hypothesized that the QOLIBRI would have satisfactory metric properties at 12 months post-injury in individuals with TBI of all severities.

\section{Methods \\ Design and study population}

We conducted a cross-sectional study with 204 adult patients (age $\geq 16$ years) post-TBI and measured HRQoL and post-injury functioning 12 months after their injury. The data were obtained from two Norwegian patient cohorts. Each cohort was participating in a large longitudinal research project assessing functioning and rehabilitation after sustaining a TBI. Cohort 1 consisted of 126 patients with severe TBI (STBI) according to the Glasgow Coma Scale (GCS) who were admitted to the Trauma Referral Centres of the four health regions of Norway in 2010. The inclusion criteria for this cohort were patients admitted to the hospital within $72 \mathrm{~h}$ post-injury who met the definition of STBI based on the lowest unsedated GCS score $\leq 8$ in the first $24 \mathrm{~h}$ post-injury. Cohort 2 comprised 78 patients with mild TBI (MTBI) according to the GCS who were admitted to the neurosurgical department of Oslo University Hospital (OUH) from January 2010 through June 2011. The inclusion criteria for the MTBI cohort were admission to the OUH neurosurgical department, a GCS score of 13-15 and persisting postconcussion symptoms at an outpatient control at OUH 6-8 weeks post-injury. For both cohorts, the exclusion criteria were chronic subdural haematoma, pre-injury cognitive disability interfering with the assessment of outcome, severe psychiatric disease and drug abuse. Figure 1 shows a flow chart of the patient inclusion process. 


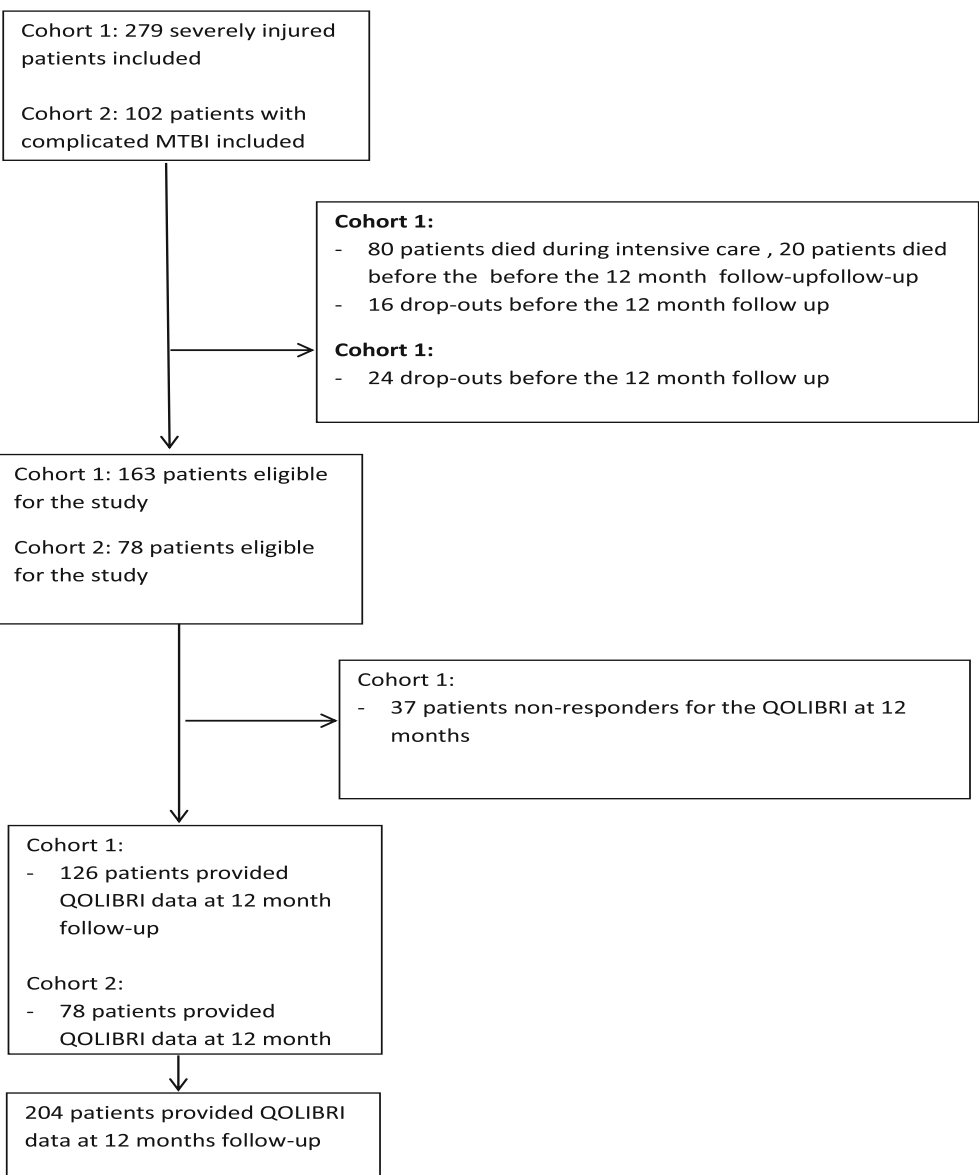

Fig. 1 Flow chart of the patient inclusion

\section{Measurements}

All instruments were administered 12 months post-injury.

The QOLIBRI consists of 37 items that generate 6 subscales and a total score [11, 21]. A 5-point Likert scale ranging from 1 (not at all satisfied/bothered) to 5 (very satisfied/bothered) is used to assess satisfaction with Cognition, Self, Daily Life and Autonomy, and Social Relationships as well as feeling bothered by Emotions and Physical Problems $[11,25]$. The QOLIBRI is scored according to an algorithm published by von Steinbüchel et al. [11]. Missing data were handled via imputation of the mean scale score if less than one-third of the responses in each subscale were missing. Raw scores were transformed into a score ranging from 0 (worst) to 100 (best) for the individual subscales, and a total scale score was also calculated.

The Rivermead Post-concussion Questionnaire (RPQ) is a self-report questionnaire measuring the severity of post-concussion symptoms following MTBI [26] and has previously been employed in populations with TBI of mixed severities [15]. This 16-item questionnaire assesses physical, emotional and cognitive symptoms after brain injury. Each item is scored from 0 (no problems) to 4 (severe problems), with a summary score ranging from 0 (best) to 64 (worst). An item score of 1 is rescored as 0 [26]. The RPQ was administered 12 months post-injury. Missing data were completed using the symptom profile reported in the patient's medical record.

The Hospital Anxiety and Depression Scale (HADS) is a 14-item measure that has been validated for persons with TBI $[27,28]$. The items of the HADS are rated on a scale ranging from 0 to 3 . The score ranges from 0 to 42 (from best to worst) [27] and is used as an indicator of psychological distress. HADS scores between 15 and 18 are considered to indicate potentially clinically significant psychological distress requiring treatment, and people with scores of 19 and higher are considered to suffer from clinically significant psychological distress requiring treatment [27].

Global functioning and recovery were assessed using the Glasgow Outcome Scale-Extended (GOSE). The GOSE measures global functioning through a structured interview $[29,30]$. According to the GOSE, patient status is 
categorized from 1 (dead) to 8 (upper good recovery). GOSE scores of 3-4 represent severe disability; scores of $5-6$, moderate disability; and scores of 7-8, good recovery.

\section{Sociodemographic and injury-related information}

The following sociodemographic variables were documented: sex, age at injury, and marital status. Education was categorized into two groups: low: fewer than 13 years of education; high: a university education. Employment status pre-injury and at 12 months post-injury was recorded and categorized as follows: being employed or a student; receiving sick leave, vocational or medical rehabilitation benefits, social security support or a disability pension; being unemployed; and being retired or a homemaker. Missing data for education were imputed based on the education required for the patient's type of work.

The following injury-related data were assessed: GCS score [31], duration of post-traumatic amnesia (PTA), Abbreviated Injury Scale (AIS) score [32] and cause of injury. The lowest GCS score within the first $24 \mathrm{~h}$ postinjury, or at the site of injury in cases of pre-hospital intubation, was registered. The AIS grades the severity of each separate injury from 1 (minor injury) to 6 (maximal injury). The AIS score of the most severe brain injury, AIS-head, was recorded.

\section{Procedures and ethics}

Baseline information was collected at the time of admission and from the Ulleval Trauma Registry at OUH [33]. At follow-up, the participants' level of functioning and HRQoL were assessed using self-report questionnaires, clinical tests and structured patient interviews. Written informed consent for participation in the study was obtained, and the study was approved by the Regional Committee for Medical Research Ethics (\#S-08378a (Cohort 1) and \#171.08 (Cohort 2). None of the authors have any competing interests in the manuscript.

\section{Data analysis and statistics}

Descriptive statistics were presented as means and standard deviation (SD) or medians and interquartile range (IQR). Correlations were analysed with Spearman's $\rho$ or Pearson's $r$. Differences in continuous variables between groups were tested using independent sample ttests or Mann-Whitney U tests.

The psychometric properties of the QOLIBRI were examined at the item level (A) and the scale level (B). The internal consistency of the scales was investigated, and item response theory/Rasch analysis was applied to test the fit of the items to the scale.

A) The responses to the items were checked to assess whether they were distributed throughout the entire range of possible options ( 1 to 5 , "not at all" to "very"). In accordance with previous work by von Steinbüchel et al. [11], we used the WHOQOL group's endorsement index (1998) to conduct the item frequency analysis. The distributions were examined for frequency problems to identify whether any two adjacent response categories had a sum of less than $10 \%$ of the total number of responses. Additionally, floor and ceiling effects were examined. A floor or ceiling effect was defined as $>60 \%$ of the cases having the maximum or minimum score on a given QOLIBRI subscale [11]. Each item was also assessed for skewness. Extreme skewness can reduce the probability that a scale will show strong correlations with other measures, thus reducing its precision and reliability. Extreme skewness can also indicate a deficit in the ability of different categories to appropriately discriminate responses to the target construct. Conventionally, items with skewness $>1$ are considered for removal; however, in accordance with the international study on the QOLIBRI, some moderately skewed items (1.0-1.3) were accepted to capture the range of disability [11].

B) The internal consistency of the QOLIBRI subscales and the total scale was examined using Cronbach's alpha. Cronbach's alpha $\geq 0.70$ is considered acceptable, and values $\geq 0.90$ are considered excellent [34]. The fit of the individual items within each subscale was tested by determining the correlation of each item with the total of the other items in its respective scale, and the corrected item-total correlations (CITCs) were calculated. In general, CITCs should be above 0.40 (WHOQOL group, [16]).

Additionally, a Rasch analysis of all items in the six subscales was performed to assess the fit of the items to the scale and to determine whether the ordinal scores fit the interval scaling requirements. No items were very skewed, and all categories had more than 10 responses. The ordering of response options and the item locations with standard error and fit (residual value with the Chisquare statistic and the corresponding probability value) were reported for each item. A standardized residual value greater than \pm 2.5 and a probability value $<0.001$ are considered as misfits of an item $[35,36]$. Bonferronicorrected significance levels $(0.05 /$ number of items in the subscale) were used in the Rasch analysis. Targeting was evaluated by examining the hierarchical distribution of the items and their response levels and was compared to the distribution of the patients along the same metric scale. Rasch analyses were performed using RUMM2030 software. 
Factor analysis was performed to study the structure of the Norwegian version of the QOLIBRI regarding the total scale and its subscales. Dimensionality was investigated using principle component analysis (PCA). We tested both a forced one-factor solution and a six-factor solution. Based on Kaiser's criterion, we extracted all factors with eigenvalues $>1$ and applied an oblique rotation (promax method with an assumption of correlated scales). Finally, a confirmatory factor analysis (CFA) using structural equation modelling (SEM) was performed. The objective of CFA is to determine whether the data fit a hypothesized measurement model. This hypothesized model is based on previous analytic research and, in our study, on data from patients with mild-severe TBI $[11,21]$. The analyses were conducted after imputation of missing values. To estimate the parameters, the maximum likelihood estimation procedure was applied in the CFA. The model fit of the QOLIBRI model was evaluated using Chi-square statistics, the Comparative Fit Index (CFI), the TuckerLewis Index (TLI), the Root Mean Square Error of Approximation (RMSEA), and the Standardized Root Mean Square Residual (SRMR). The fit statistics were interpreted based on the cut-off criteria proposed by $\mathrm{Hu}$ and Bentler [37]. Accordingly, a good fit of the model was indicated by non-significant Chi-square statistics, CFI and TLI $>0.95$, SRMR $<0.07$, and RMSEA $<0.06$ using StataSE13.

\section{Results}

\section{Descriptive statistics}

The mean age of the 204 patients was 37.6 (SD 15.4) years; $72 \%$ were men, and $41 \%$ had a high level of education. Most (81\%) individuals had been working or were students before they experienced the TBI. The demographic information is presented in Table 1 . More than $60 \%$ of the patients were severely injured according to the GCS criteria. The patients had a mean GCS score of 9.3 (SD 4.5). According to the GOSE at 12 months postinjury, 5.9\% had severe disability, $45.5 \%$ had moderate disability, and $48.5 \%$ had good recovery. The injuryrelated characteristics of the patients are presented in Table 2.

At 12 months, $88 \%$ of the patients with STBI had returned home and $12 \%$ lived in institutional care facilities; whereas all participants with MTBI lived at home. $54.8 \%$ of the patients were still on sick leave or were receiving (vocational) rehabilitation benefits or a disability pension.

There were less than 5\% missing responses for each QOLIBRI item. HADS scores were available for 98\%, RPQ scores for $99 \%$ and GOSE scores for $99 \%$ of the patients (see Table 1).

The mean QOLIBRI score was 67.0 (SD 19.1) (see Table 3). There were no differences in the total QOLIBRI
Table 1 Demographic information and post-injury functioning for the study population $(n=204)$

\begin{tabular}{ll}
\hline Demographic information & \\
\hline Age, mean (SD) & $37.6(15.4)$ \\
Gender (men) & $147(72.1 \%)$ \\
Marital status & \\
- Married/living with a partner & $98(48.0 \%)$ \\
- Single/Divorced/Cohabitating ${ }^{a}$ & $105(51.5 \%)$ \\
- Unknown & $1(0.5 \%)$ \\
Education & \\
- Low & $121(59.3 \%)$ \\
- High & $83(40.7 \%)$ \\
Pre-injury employment status & \\
- Employed/student & $165(80.9 \%)$ \\
- Sick-leave/vocational or medical rehabilitation/ & $17(8.3 \%)$ \\
social security support/disability pension & \\
- Unemployed & $7(3.4 \%)$ \\
- Retired/homemaker & $12(5.9 \%)$ \\
- Unknown & $3(1.5 \%)$ \\
Employment status at 12 months & \\
- Employed/student & \\
- Sick-leave/vocational or medical rehabilitation/ & $69(54.8 \%)$ \\
social security support/disability pension & \\
- Unemployed & $6(4.8 \%)$ \\
- Retired/homemaker & $13(10.3 \%)$ \\
- Unknown & $6.0(\mathrm{IQR} 6.0-8.0)$ \\
ROSE at 12 months ( $n=202)$ & $14(\mathrm{IQR} 2.8-25)$ \\
HADS at 12 months ( $n=201)$ & \\
\hline GOSE Glas & \\
\hline
\end{tabular}

GOSE Glasgow Outcome Scale-Extended, RPQ Rivermead Post-concussion Questionnaire, HADS Hospital Anxiety and Depression Scale ancludes apartment sharing

score between the cohorts, however, the patients with STBI reported 7.0 points better score on the Cognition subscale $(p=0.026)$ than reported by the MTBI patients. In addition, STBI patients showed a trend towards better higher score on the Self subscale by 5.9 points $(p=0.067)$ and on the Emotions subscale $(p=0.055)$ (data not shown).

According to the HADS results, $22 \%$ of the patients demonstrated symptoms of psychological distress at 12 months. Thirteen patients $(6.5 \%)$ had mild to moderate symptom pressure, whereas 31 (15.5\%) patients had scores $\geq 15$ points, reflecting the presence of symptoms of anxiety and depression that required treatment (not shown in Table 1).

\section{Item characteristics and internal consistency}

The reliability analysis (Table 4) showed that all CITCs within the respective subscales were greater than 0.40 . 
Table 2 Injury related data of the participants

\begin{tabular}{|c|c|}
\hline \multicolumn{2}{|l|}{ Injury characteristics } \\
\hline GCS $(n=204)$ mean (SD) & $9.3(4.5)$ \\
\hline Median (IQR) & $8(6-15)$ \\
\hline AIS-head mean (SD) $(n=202)$ & $3.4(1.4)$ \\
\hline \multicolumn{2}{|l|}{ PTA } \\
\hline \multicolumn{2}{|l|}{ MTBI $(n=78)$} \\
\hline$<1 \mathrm{~h}$ & $57(73.1 \%)$ \\
\hline $1 \mathrm{~h}-<24 \mathrm{~h}$ & $16(20.5 \%)$ \\
\hline $24 \mathrm{~h}-7$ days & $1(1.3 \%)$ \\
\hline Missing & $4(5.1 \%)$ \\
\hline \multicolumn{2}{|l|}{ STBI $(n=126)$} \\
\hline$<1$ week & $29(23.0 \%)$ \\
\hline $1-2$ weeks & $17(13.5 \%)$ \\
\hline $2-3$ weeks & $12(9.5 \%)$ \\
\hline 3-4weeks & $12(9.5 \%)$ \\
\hline$>4$ weeks & $54(42.9 \%)$ \\
\hline Missing & $2(1.6 \%)$ \\
\hline \multicolumn{2}{|l|}{ Injury mechanism ( $n=204)$} \\
\hline - Traffic & $88(43.1)$ \\
\hline - Fall & $74(36.3)$ \\
\hline - Violence & $19(9.3)$ \\
\hline - Other & $23(11.3)$ \\
\hline
\end{tabular}

The majority of items had CITCs greater than 0.60 , and none had a CITC below 0.43 . With respect to skewness, four items were skewed slightly above 1 (satisfaction with "ability to get out and about" and "relationship with members of your family" as well as being bothered by "feeling lonely" and "feeling angry or aggressive"). These items are clinically important and showed reasonable scale fits on the other parameters.

The internal consistency of each scale is shown in Table 3. Cronbach's $\alpha$ ranged from 0.75 (Physical

Table 3 QOLIBRI mean scale scores and SDs

\begin{tabular}{lll}
\hline & Mean (SD) & $a$ \\
\hline Cognition & $65.6(21.9)$ & 0.92 \\
Self & $62.3(22.4)$ & 0.91 \\
Daily life and autonomy & $66.3(23.9)$ & 0.90 \\
Social relationships & $69.4(21.7)$ & 0.85 \\
Emotions & $73.1(24.4)$ & 0.88 \\
Physical problems & $67.4(22.9)$ & 0.75 \\
QOLIBRI Total & $67.0(19.1)$ & 0.96 (all items)
\end{tabular}

Cronbach's a for all data
Problems) to 0.92 (Cognition) and was 0.96 for the total score. In this respect, the Norwegian QOLIBRI meets the necessary criteria to be applied in research and to provide acceptable and reliable assessments at the individual level.

\section{Response categories and targeting of the subscales}

The results of the Rasch analysis are shown in Table 5. Concerning the Cognition subscale, all items revealed ordered response categories. The overall Chi-square statistic was $17.05(\mathrm{df}=14, p=0.25)$, indicating a fit to the Rasch model. All items in the Cognition subscale also fit the model. The mean person location was 1.27 (SD 1.95) indicating a higher level of satisfaction with cognitive function of the subjects than reflected by the subscale items.

Additionally, all items of the Self subscale were characterized by ordered response categories. The overall Chi-square statistic was $21.20(\mathrm{df}=14, p=0.10)$, indicating a fit of the Self subscale to the Rasch model. All items in the Self subscale also fit the model. The mean person location was 0.86 (SD 1.75) indicating a slightly higher level of satisfaction with self-perception of the subjects than reflected by the subscale items.

Items 2 and 5 of the Daily Life and Autonomy subscale revealed disordered thresholds and were rescored $(1,1$, $2,2,3)$ and $(1,1,2,3,4)$, respectively. After rescoring the items, the overall Chi-square statistic was 20.11 (df $=14, p=0.13$ ), indicating a fit of this subscale to the Rasch model. All items of the Daily Life and Autonomy subscale subscale also fit the model. The mean person location was 0.82 (SD 1.60), indicating that the subjects had a slightly higher level of daily activity than reflected by the subscale items.

Items 4 and 5 of the Social Relationships subscale demonstrated disordered thresholds and were rescored $(1,1,2,3,4)$. The overall Chi-square statistic was 20.58 ( $\mathrm{df}=14, p=0.06$ ), indicating a fit of this subscale to the Rasch model. The mean person location was 1.03 (SD 1.50), implying that the subjects had a moderately higher level of social participation than the average of the subscale.

Disordered thresholds were found for items 3 and 4 of the Emotions subscale, and these items were therefore rescored $(1,2,2,3,4)$ and $(1,2,2,3,3)$, respectively. The overall Chi-square statistic was $25.72(\mathrm{df}=10, p=$ 0.004), revealing a misfit of this subscale to the Rasch model, likely due to the misfit of item 4 (Table 5). The mean person location was 1.03 (SD 1.50), demonstrating that the subjects had a higher level of emotional function than reflected by the subscale items.

The disordered thresholds of items 1 through 4 on the Physical Problems subscale were rescored $(1,1,2,2,3)$. The overall Chi-square statistic was $8.05(\mathrm{df}=10, p=$ 
Table 4 Item descriptives and scale reliability analyses

\begin{tabular}{|c|c|c|c|c|c|c|c|}
\hline & Item & $\begin{array}{l}\text { Item } \\
\text { descriptives } \\
\text { Mean }\end{array}$ & SD & $\begin{array}{l}\text { Percent } \\
\text { missing }\end{array}$ & Skewness & CITC & $\begin{array}{l}\text { Alpha if } \\
\text { item } \\
\text { removed }\end{array}$ \\
\hline \multirow[t]{7}{*}{ Cognition } & Concentrate & 3.34 & 1.19 & 0.5 & -0.48 & 0.788 & 0.897 \\
\hline & $\begin{array}{l}\text { Express } \\
\text { yourself }\end{array}$ & 3.83 & 1.01 & 0.5 & -0.55 & 0.785 & 0.898 \\
\hline & Remember & 3.22 & 1.20 & 1.5 & -0.31 & 0.676 & 0.911 \\
\hline & $\begin{array}{l}\text { Plan and } \\
\text { problem solve }\end{array}$ & 3.80 & 1.09 & 1.0 & -0.73 & 0.749 & 0.901 \\
\hline & Decisions & 3.71 & 0.96 & 0 & -0.47 & 0.731 & 0.904 \\
\hline & Find way & 3.93 & 1.00 & 1.0 & -0.81 & 0.673 & 0.909 \\
\hline & Speed of thinking & 3.56 & 1.05 & 1.5 & -0.55 & 0.803 & 0.896 \\
\hline \multirow[t]{7}{*}{ Self } & Energy & 3.24 & 1.18 & 0.5 & -0.35 & 0.697 & 0.895 \\
\hline & Control emotions & 3.42 & 1.17 & 1.0 & -0.49 & 0.737 & 0.890 \\
\hline & Motivation & 3.46 & 1.12 & 0.5 & -0.50 & 0.776 & 0.886 \\
\hline & Self-esteem & 3.58 & 1.04 & 1.0 & -0.39 & 0.638 & 0.900 \\
\hline & Way you look & 3.70 & 1.16 & 0.5 & -0.60 & 0.655 & 0.899 \\
\hline & Self-perception & 3.56 & 0.99 & 1.5 & -0.40 & 0.790 & 0.886 \\
\hline & Own future & 3.47 & 1.16 & 1.5 & -0.57 & 0.758 & 0.887 \\
\hline \multirow[t]{7}{*}{ Daily life and autonomy } & Independence & 3.70 & 1.24 & 1.0 & -0.67 & 0.762 & 0.876 \\
\hline & Get out and about & 3.96 & 1.32 & 0.5 & -1.07 & 0.663 & 0.887 \\
\hline & Domestic activities & 3.78 & 1.11 & 1.5 & -0.73 & 0.715 & 0.887 \\
\hline & Run personal finances & 3.73 & 1.21 & 1.0 & -0.78 & 0.616 & 0.893 \\
\hline & Participation in work & 3.40 & 1.32 & 4.9 & -0.53 & 0.693 & 0.884 \\
\hline & Social-leisure participation & 3.37 & 1.24 & 4.9 & -0.30 & 0.646 & 0.889 \\
\hline & In charge of life & 3.61 & 1.20 & 2.0 & -0.51 & 0.831 & 0.868 \\
\hline \multirow[t]{6}{*}{ Social relationships } & Affection towards others & 3.96 & 1.08 & 0.5 & -0.92 & 0.639 & 0.827 \\
\hline & Family & 4.14 & 0.96 & 0.5 & -1.13 & 0.632 & 0.830 \\
\hline & Friends & 3.93 & 1.07 & 0.5 & -0.77 & 0.723 & 0.812 \\
\hline & Partner & 3.68 & 1.32 & 1.5 & -0.72 & 0.690 & 0.818 \\
\hline & Sex life & 3.26 & 1.37 & 2.5 & -0.24 & 0.556 & 0.849 \\
\hline & Attitudes of others & 3.71 & 1.01 & 2.0 & -0.54 & 0.643 & 0.828 \\
\hline \multirow[t]{5}{*}{ Emotions } & Loneliness & 4.15 & 1.09 & 1.5 & -1.25 & 0.713 & 0.850 \\
\hline & Boredom & 3.88 & 1.15 & 2.0 & -0.93 & 0.671 & 0.859 \\
\hline & Anxiety & 3.86 & 1.31 & 2.0 & -0.83 & 0.752 & 0.840 \\
\hline & Depression & 3.78 & 1.20 & 2.9 & -0.71 & 0.836 & 0.819 \\
\hline & Anger/aggression & 3.96 & 1.22 & 2.0 & -1.08 & 0.581 & 0.880 \\
\hline \multirow[t]{5}{*}{ Physical condition } & Slowness/clumsy & 3.92 & 1.21 & 2.0 & -0.99 & 0.463 & 0.729 \\
\hline & Other injuries & 3.54 & 1.43 & 1.5 & -0.62 & 0.578 & 0.688 \\
\hline & Pain & 3.63 & 1.39 & 1.5 & -0.66 & 0.488 & 0.732 \\
\hline & See/hear & 3.96 & 1.22 & 2.0 & -0.99 & 0.426 & 0.741 \\
\hline & TBI effects & 3.43 & 1.19 & 2.9 & -0.32 & 0.663 & 0.662 \\
\hline
\end{tabular}

CITC corrected item-total correlation, SD standard deviation

0.62), indicating a fit of this subscale to the Rasch model. The mean person location was 0.55 (SD 1.33), suggesting that the subscale was targeting rather well between subjects and the subscale items.

\section{Exploratory factor analysis}

The results of the two factor analyses (PCA) are shown in Table 6. A single-factor and a forced 6-factor solution were produced to compare the structure of the 
Table 5 Measures of item difficulty and fit from Rasch analysis of each of the QOLIBRI scales

\begin{tabular}{|c|c|c|c|c|c|c|}
\hline Item & Content & Location & SE & $\begin{array}{l}\text { Standardized } \\
\text { residual }\end{array}$ & $x^{2}$ & Prob. \\
\hline \multicolumn{7}{|c|}{ Cognition } \\
\hline | 1 & Concentrate & 0.76 & 0.10 & -1.01 & 2.33 & 0.31 \\
\hline 12 & Express yourself & -0.67 & 0.11 & -1.27 & 1.79 & 0.41 \\
\hline 13 & Remember & 0.95 & 0.10 & 2.36 & 1.58 & 0.45 \\
\hline 14 & $\begin{array}{l}\text { Plan and solve } \\
\text { problems }\end{array}$ & -0.29 & 0.11 & -0.15 & 0.76 & 0.69 \\
\hline 15 & Decisions & -0.37 & 0.11 & 0.33 & 2.62 & 0.27 \\
\hline 16 & Find a way about & -0.63 & 0.11 & 1.61 & 4.38 & 0.11 \\
\hline 17 & Speed of thinking & 0.24 & 0.11 & -1.91 & 3.59 & 0.16 \\
\hline \multicolumn{7}{|l|}{ Self } \\
\hline 11 & Energy & 0.54 & 0.10 & 1.14 & 1.81 & 0.41 \\
\hline 12 & Motivation & 0.18 & 0.10 & -0.10 & 0.36 & 0.83 \\
\hline 13 & Self-esteem & 0.04 & 0.10 & -1.23 & 3.15 & 0.21 \\
\hline 14 & Way of look & 0.26 & 0.10 & 1.69 & 1.79 & 0.41 \\
\hline 15 & Achievements & 0.37 & 0.10 & 1.21 & 5.38 & 0.07 \\
\hline 16 & Self-perception & -0.28 & 0.11 & -1.81 & 5.04 & 0.08 \\
\hline 17 & Own future & 0.16 & 0.10 & -0.58 & 3.67 & 0.16 \\
\hline \multicolumn{7}{|c|}{ Daily life and Autonomy } \\
\hline 11 & Independence & -0.18 & 0.09 & -0.93 & 2.28 & 0.32 \\
\hline 12 & Get out and about & -0.11 & 0.13 & -0.66 & 3.22 & 0.20 \\
\hline 13 & Domestic activities & -0.42 & 0.10 & 0.17 & 1.95 & 0.38 \\
\hline 14 & $\begin{array}{l}\text { Run personal } \\
\text { finances }\end{array}$ & -0.19 & 0.09 & 2.27 & 2.61 & 0.27 \\
\hline 15 & $\begin{array}{l}\text { Participation in } \\
\text { work/education }\end{array}$ & -0.80 & 0.10 & 1.01 & 0.81 & 0.67 \\
\hline 16 & $\begin{array}{l}\text { Social and leisure } \\
\text { activities }\end{array}$ & -0.22 & 0.09 & 1.88 & 2.74 & 0.25 \\
\hline 17 & $\begin{array}{l}\text { In charge own } \\
\text { of life }\end{array}$ & -0.13 & 0.10 & -3.05 & 6.51 & 0.04 \\
\hline \multicolumn{7}{|c|}{ Social Relationships } \\
\hline 11 & Affection to others & -0.33 & 0.09 & 0.34 & 5.49 & 0.06 \\
\hline 12 & Family members & -0.73 & 0.10 & -0.04 & 1.46 & 0.48 \\
\hline 13 & Friends & -0.53 & 0.10 & -0.98 & 8.25 & 0.02 \\
\hline 14 & Partner & 0.55 & 0.09 & -0.74 & 0.82 & 0.66 \\
\hline 15 & Sex life & 1.15 & 0.10 & 2.12 & 3.31 & 0.19 \\
\hline 16 & Attitudes of others & -0.12 & 0.10 & 0.62 & 1.26 & 0.53 \\
\hline \multicolumn{7}{|c|}{ Emotions } \\
\hline 11 & Loneliness & -0.20 & 0.10 & -0.23 & 3.23 & 0.20 \\
\hline 12 & Boring & 0.34 & 0.10 & 0.72 & 0.64 & 0.73 \\
\hline 13 & Anxiety & 0.38 & 0.11 & -0.57 & 4.82 & 0.09 \\
\hline 14 & Depression & -0.85 & 0.17 & -2.28 & 15.11 & 0.0005 \\
\hline 15 & Anger & 0.34 & 0.09 & 2.26 & 1.93 & 0.38 \\
\hline
\end{tabular}

Table 5 Measures of item difficulty and fit from Rasch analysis of each of the QOLIBRI scales (Continued)

Physical Problems

\begin{tabular}{lllllll} 
I1 & Slowness/clumsy & -0.19 & 0.13 & 1.16 & 0.12 & 0.94 \\
12 & Other injuries & 0.37 & 0.12 & 0.20 & 1.00 & 0.60 \\
I3 & Pain & 0.22 & 0.12 & 1.03 & 0.13 & 0.93 \\
I4 & See/hear & -0.34 & 0.12 & 1.02 & 0.15 & 0.93 \\
I5 & TBI effects & -0.07 & 0.09 & -2.07 & 6.65 & 0.04 \\
\hline $\begin{array}{l}\text { Bonferroni corrected significance level } \\
\text { SE standard error }\end{array}$
\end{tabular}

Norwegian version of the QOLIBRI to the results of the analysis of the QOLIBRI $[11,38]$. The loadings on the single-factor solution for the total score showed an overall good fit in the first five scales, with the single factor solution as only four loadings were below 0.6 according to the First Principal Component scores, as shown in Table 6. Items in the Physical Problems scale had a weaker fit, with 4 factor loadings $<0.6$, although none of the items showed a poor fit (loadings $<0.45$ ).

The results of the 6-factor solution showed that most of the QOLIBRI scales loaded on the appropriate factors, i.e., their home subscale, and the PCA reproduced the overall structure of the international version of the QOLIBRI. Four items did not load on their home scale; "Achievements" loaded on Cognition instead of Self, "Social \& leisure activities" loaded on Self instead of Daily Life, and "Slow/clumsiness" loaded on Daily Life instead of Physical Problems. In total, there were 16 cross-loadings (of the 37 items), and the social scale and the physical scale had the most cross-loadings (Table 6).

\section{Confirmatory factor analysis}

SEM was used to assess the measurement structure of the QOLIBRI. Due to the high inter-correlations of the six latent factors (range of $r=0.55-0.85$ ), a second-order HRQoL factor was included, as proposed by von Steinbüchel et al. [11]. Subsequently, the final model consisted of the six latent variables at the firstorder level and HRQoL as a second-order latent variable (Fig. 2). The model fit statistics of the secondorder model of an overall HRQoL model indicated a moderate fit to the observed data $(\mathrm{CFI}=0.86$, TLI $=$ 0.85, RMSEA $=0.076$, SRMR $=0.061, x^{2}=1315.76, \mathrm{df}$ $=623, p$-value $<0.001)$. The model meets the SRMR criterion where values $<0.08$ are deemed acceptable in combination with TLI $<0.95$, but not the RMSEA and the CFI criteria for satisfactory fit [37]. Thus, according to the test scores, the SEM analysis indicates that the HRQoL partially fits; however, the fit of the QOLIBRI total score, representing a common overall HRQoL model, fits less well. 
Table 6 Principal component analysis of the Norwegian QOLIBRI items

\begin{tabular}{|c|c|c|c|c|c|c|c|c|c|}
\hline Scale & Item & First principal component & Communality & Factor 1 & Factor 2 & Factor 3 & Factor 4 & Factor 5 & Factor 6 \\
\hline \multicolumn{10}{|c|}{ Cognition } \\
\hline & Concentrate & 0.717 & 0.779 & 0.890 & & & & & 0.292 \\
\hline & Express yourself & 0.764 & 0.729 & 0.820 & & & & & \\
\hline & Remember & 0.685 & 0.602 & 0.569 & & & & & 0.350 \\
\hline & Plan and problem solve & 0.736 & 0.678 & 0.739 & & & & & \\
\hline & Decisions & 0.721 & 0.676 & 0.775 & & & & & \\
\hline & Find way & 0.727 & 0.644 & 0.741 & & & & & \\
\hline & Speed of thinking & 0.751 & 0.777 & 0.915 & & & & & \\
\hline \multicolumn{10}{|l|}{ Self } \\
\hline & Energy & 0.719 & 0.696 & 0.325 & 0.506 & & & & 0.345 \\
\hline & Control emotions & 0.726 & 0.670 & 0.355 & 0.613 & & & & \\
\hline & Motivation & 0.769 & 0.753 & & 0.758 & & & & \\
\hline & Self-esteem/Achievements & 0.608 & 0.700 & & 0.968 & & & & \\
\hline & Way you look & 0.758 & 0.627 & 0.475 & & & & & \\
\hline & Self-perception & 0.776 & 0.747 & & 0.708 & & & & \\
\hline & Own future & 0.763 & 0.692 & & 0.680 & & & & \\
\hline \multicolumn{10}{|c|}{ Daily life } \\
\hline & Independence & 0.663 & 0.759 & & & & 0.814 & & \\
\hline & Get out and about & 0.593 & 0.675 & & 0.291 & & 0.736 & & \\
\hline & Domestic activities & 0.737 & 0.648 & 0.311 & & & 0.478 & & \\
\hline & Basic personal needs & 0.614 & 0.518 & & & & 0.541 & & \\
\hline & Run personal finances & 0.671 & 0.598 & & & & 0.583 & & \\
\hline & Participation work/education & 0.730 & 0.642 & & 0.620 & & & & \\
\hline & Social and leisure activities & 0.813 & 0.726 & & & & 0.441 & & \\
\hline \multicolumn{10}{|l|}{ Social } \\
\hline & Affection towards others & 0.666 & 0.636 & & 0.456 & & & 0.300 & \\
\hline & Family members & 0.604 & 0.594 & 0.404 & & & & 0.487 & \\
\hline & Friends & 0.722 & 0.691 & 0.268 & & & & 0.452 & \\
\hline & Partner & 0.534 & 0.756 & & & & & 0.991 & \\
\hline & Sex life & 0.549 & 0.651 & -0.354 & & & & 0.841 & \\
\hline & Attitudes of others & 0.632 & 0.579 & & & & & 0.619 & \\
\hline \multicolumn{10}{|c|}{ Emotions } \\
\hline & Loneliness & 0.614 & 0.658 & & & 0.748 & & & \\
\hline & Boredom & 0.542 & 0.662 & & & 0.806 & & & \\
\hline & Anxiety & 0.609 & 0.729 & & & 0.827 & & & \\
\hline & Depression & 0.707 & 0.808 & & & 0.798 & & & \\
\hline & Anger/aggression & 0.560 & 0.595 & & -0.283 & 0.696 & & & \\
\hline \multicolumn{10}{|c|}{ Physical } \\
\hline & Slow/clumsiness & 0.490 & 0.648 & & & & 0.751 & -0.323 & \\
\hline & Other injuries & 0.491 & 0.588 & & & & & & 0.612 \\
\hline & Pain & 0.566 & 0.504 & & & 0.376 & & & 0.373 \\
\hline & See/hear & 0.479 & 0.567 & 0.264 & & -0.285 & & & 0.673 \\
\hline & TBI effects & 0.653 & 0.695 & & & & & & 0.634 \\
\hline
\end{tabular}




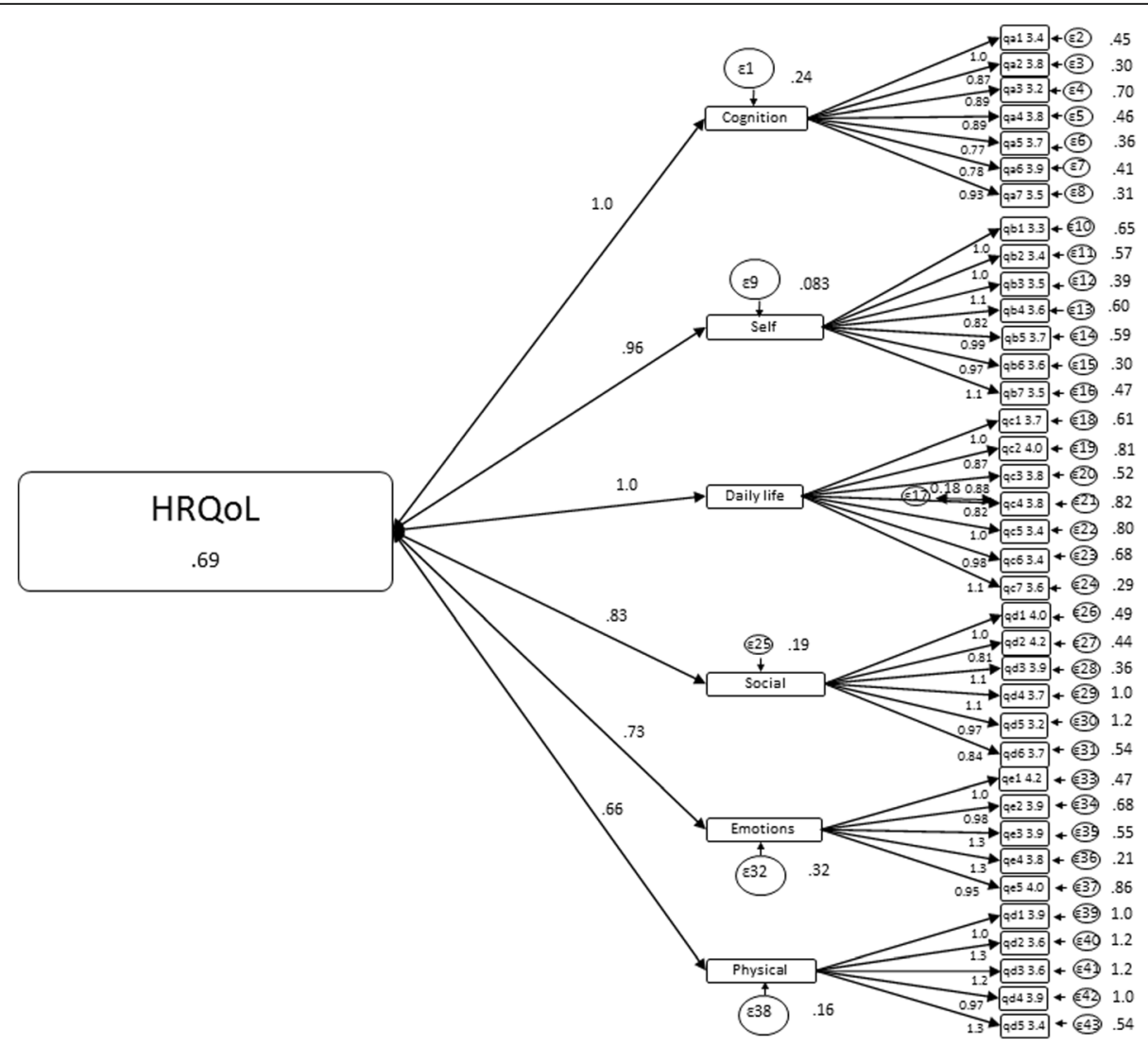

Fig. 2 Structural equation model of the structure of the Norwegian QOLIBRI (standardized estimates)

\section{Discussion}

The translation of the Norwegian version of the QOLIBRI was performed according to international standards and the requirements of its developers [11]. However, to administer the QOLIBRI in international studies, its metric properties have to be established as part of the cross-cultural development of the instrument. In the current study, we investigated the metric properties of the Norwegian version of the QOLIBRI with respect to its internal consistency, scale properties and factor structure. By testing all the subjects in this study at 12 months post-injury, potential ceiling effects in individuals in the spectrum of relatively mild to severe TBI, and other metric differences across the TBI subgroups could be evaluated.

The demographic characteristics of this study population are consistent with those of other studies, and the educational level was between those of the international (35\%) and Finnish (50\%) studies [11,39]. The proportion of patients with STBI based on the GCS criteria in this study was also equivalent to that in other QOLIBRI studies; however, the current study contained a larger percentage of patients with good recovery $(48.5 \%)$ than the international $(28 \%)$ and Finnish studies (1.3\%).
The patients were distributed throughout the entire spectrum of TBI severities. In this respect, the current study captured the variability in the HRQoL of TBI patients 12 months post-injury. However, the present results showed that STBI patients reported better cognitive functioning on the QOLIBRI subscale than the MTBI patients. The reduced awareness and longer rehabilitation periods with less exposure to job and other environmental demands for the STBI patients might be explanatory factors of the higher self-reported satisfaction with their cognitive functioning. Sasse et al. reported that a reduced awareness was associated with a higher satisfaction with cognitive functioning on the QOLIBRI [40]. Moreover, other studies have shown that people with reduced selfawareness report a higher HRQoL $[41,42]$. Although QoL has been suggested to be overestimated due to reduced awareness, it is difficult to disregard on an individual's perceived QoL. In addition, the social and emotional dimensions seem to be less overestimated than the physical dimension; this finding supports the validity of applying self-reported QoL also in the STBI group [43]. This might be explained by an overestimation of functioning by STBI patients than they have. Nonetheless, reliable HRQoL results have been obtained in other studies of patients with reduced cognitive functioning [44]. 
The internal consistency of the Norwegian QOLIBRI was generally satisfactory to excellent in this sample, in which all patients were severely injured or had a protracted course of recovery after MTBI. The lowest reliability according to Cronbach's $\alpha$ was observed in the Physical Problems subscale, which covers a range of possible motor and sensory functions that can be expected to present differently within and between STBI and MTBI patients [45]. In accordance with the international study, the present result could be interpreted as indicating that the QOLIBRI captured the HRQoL of individuals along the entire spectrum of TBI severity [11].

The Rasch analysis indicated that the scoring categories adequately differentiated all items within the Cognition and Self subscales. For the other subscales, a couple of questions in each scale displayed disordered response thresholds for the scoring categories, with only three or four categories actually differentiating the level of the targeted item. Very few ordinal measurements fulfil scaling properties with distinct thresholds for the entire range of scoring options across all items [46]. Therefore, the results of the items of the QOLIBRI are deemed to be rather good. All subscales and their items fit the Rasch model, except for the depression item in the Emotion subscale, indicating a slight diversion in the anxiety and depression dimension that is also reflected in the HADS which calculates anxiety and depression separately [27, 28]. This finding supports the notion that the summary scores for each subscale provide valid measurements, with the exception of the Emotion subscale. The unidimensionality of QOLIBRI regarding emotions was documented in the study by von Steinbüchel et al. [11]. Rasch analyses are population-specific, and slight misfit to a single item is common $[47,48]$. However, one could allocate for analysing anxiety and depression separately when applying the Emotional subscale of the QOLIBRI in the present population. The targeting of a scale is essential for measuring the problems of all subjects and the basis for determining the responsiveness of the measurement [49]. The subscales, with the exception of the Physical Problem subscale, targeted subjects with slightly more problems than experienced by the present population, which is not surprising given the one-year period of recovery after injury.

The PCA and SEM analyses of the Norwegian version of the QOLIBRI also supported the structure that was tested and reported by the QOLIBRI developers, with a six-factor structure in a second-order latent model [11]. The PCA showed that the QOLIBRI supports an underlying unidimensional HRQoL model. Our results are somewhat stronger than those reported in the international study [11]. In our study, the first four scales tapping on satisfaction with functioning, had a good fit, whereas the Social function scale in the international study showed a poorer fit. However, according to the SEM, our results indicate certain underlying weaknesses in the QOLIBRI model. The second order model showed moderate results, and did not quite obtain the fit criteria for a unidimensional latent HRQoL factor compared to Steinbüchel et al. [11]. However, our population included TBI patients of all severities at one point of time post-injury, whereas theirs comprised people with TBI of all severities studied at varying times after the injury. The postinjury experience might differ between these populations, which might influence the fit of the unidimensional factor structure. Similar problems were reported in the international study, where these problems may have been attributed to a large N; however, our study showed that there may be other underlying challenges as well in the QOLIBRI model.

As hypothesized, the Norwegian version of the QOLIBRI provides a subscale and total scale for different aspects of HRQoL, with acceptable psychometric properties. The six domains of the QOLIBRI covered a rich profile description, which is necessary in studies in which the changes in selfreported functioning within specific domains are of value, andthe QOLIBRI total score provides a measurement of the impact of interventions on the aggregated HRQoL.

In line with the international QOLIBRI study, the Norwegian version of the QOLIBRI demonstrated acceptable psychometric properties. In previous international studies on the development and metric properties of the QOLIBRI, most of the participating countries lacked a sufficient number of patients to confirm the factor structure in their respective languages [11]. However, a subsequent study from Finland found that the QOLIBRI was psychometrically sound [39], and a validation of the Australian version has also been published [25]. Both of these studies consisted of patients who were included in the international study. Hence, the current study is one of the first to test the factor structure of the QOLIBRI in a specific language independent from the international study. Given this context, our results support previous findings and strengthen the validity of the QOLIBRI.

The QOLIBRI was developed to capture HRQoL from the patient's perspective. The current study showed that its metric properties were somewhat weaker on the two problem scales, pertaining to Emotions and Physical functioning. Although the latter scale captures functions that are clinically relevant, physical functioning might vary largely within the TBI population, often independently of TBI severity [50]. The items of the Physical functioning scale cover specific but very different functions, such as clumsiness, hearing/vision and pain. Although these are relevant functions, they may not capture the diversity of the spectrum of physical challenges experienced after sustaining a TBI [8]. Furthermore, the items in the QOLIBRI mainly assess respondents' satisfaction and feelings of being bothered by emotional and psychosocial 
aspects following TBI, not their actual functioning per se. Hence, the assessment of HRQoL using the QOLIBRI can supplement other measures such as the GOSE in the rehabilitation of persons who have suffered a TBI.

This study has some limitations. The current study did not assess test-retest reliability because our data were from a clinical study and were not designed to be used in planned as a study of the metric properties of the QOLIBRI. However, the general results of our study do not deviate substantially from those of the international study, and we expect the test-retest reliability to be consistent between studies, as well. Furthermore, this study did not comprise results of detailed cognitive neuropsychological testing for all the patients. Only the STBI cohort underwent more comprehensive neuropsychological testing on a general basis, whereas a more extensive test battery was only administered to MTBI patients when indicated.

\section{Conclusions}

In conclusion, the results of the analysis of the Norwegian version of the QOLIBRI indicate that it has favourable psychometric properties. However, there were some weaknesses related to the QOLIBRI measurement properties of the total score when tested on a population experiencing TBI, many of whom had very severe TBI and many of whom exhibited good recovery.

\section{Abbreviations}

AIS: Abbreviated injury scale; CFI: Comparative fit index; GCS: Glasgow coma scale; GOSE: Glasgow outcome scale extended; HADS: Hospital anxiety and depression scale; HRQoL: Health related quality of life; IQR: Interquartile range; MTBI: Mild TBl; OUH: Oslo University Hospital; PCA: Principal componet analysis; PTA: Post-traumatic amnesia; QoL: Quality of life; QOLIBRI: Quality of life after brain injury; RMSEA: Root mean square error of approximation; RPQ: Rivermead post-concussion questionnaire; SD: Standard deviation; SEM: Structural equation modelling; SRMR: Standardized root mean square residual; STBI: Severe TBI; TBI: Traumatic brain injury; TLI: Tucker-Lewis Index

\section{Acknowledgements}

We acknowledge and appreciate the contributions of the TBI research teams at the Oslo University Hospital, Sunnaas Rehabilitation Hospital, University Hospital of North-Norway, Haukeland University Hospital, St. Olav's University Hospital, and Sorlandet Hospital involved in planning, design and data collection of the national multicentre study on severe traumatic brain injury. The study was in part funded by The Research Council of Norway Grant\# 8744/SFP 1108-13. All authors were financed through their research positions at Oslo University Hospital, Oslo Norway (Soberg, Roe, Brunborg and Andelic) and Institute of Medical Psychology and Medical Sociology, University Medical Centre Göttingen, Germany (von Steinbüchel) with no additional funding.

\section{Funding}

This study was in part funded by the Research Council of Norway grant number $8744 /$ SFP1108-13. The funding was related to the national multicentre study of people with severe traumatic brain injury and concerned the design of the study and data collection. The collection of data from people with mild traumatic brain injury, and the analysis, interpretation of the whole data set, and writing of the manuscript was performed within the Trauma research group at the Department of Physical Medicine and Rehabilitation at Oslo University Hospital with no additional funding. All authors have contributed with writing the manuscript within their research positions at Oslo University Hospital, Oslo Norway (Soberg, Roe, Brunborg and Andelic) and Institute of Medical Psychology and Medical Sociology, University Medical Centre Göttingen, Germany (von Steinbüchel) with no additional funding.

\section{Availability of data and materials}

The data in this originate from two national multicenter studies on traumatic brain injury, where one is still ongoing. Thus, the data will not be shared at this time.

\section{Authors' contributions}

HLS contributed in designing the study, performing the data analyses and the interpretation of the data, and in writing and critically revising the manuscript. CR contributed in the conception and design of the study, in the data collection, the data analysis and interpretation of the data, and in critically revising the manuscript. CB contributed in the data analysis and interpretation of the data, and in writing the manuscript. NvS contributed in the conception of the study, in interpreting the data analysis, and in critically revising the manuscript. NA contributed in the conception and design of the study, in the data collection, in the interpretation of the data, and in critically revising the manuscript. All authors approve the final version of the manuscript, and agree to be accountable for all aspects of the work in ensuring that questions related to the accuracy or integrity of any part of the work are appropriately investigated and resolved.

\section{Competing interests}

The authors declare that they have no competing interests.

\section{Consent for publication}

Not applicable.

\section{Ethics approval and consent to participate}

Informed consent for participation in the study was provided, and the study was approved by the Regional Committee for Medical Research Ethics (\#S-08378a (Cohort 1), and \#171.08 (Cohort 2).

\section{Author details}

${ }^{1}$ Department of Physical Medicine and Rehabilitation, Oslo University Hospital, Postbox 4950, Nydalen 0424 Oslo, Norway. ${ }^{2}$ Oslo Centre for Biostatistics and Epidemiology, Research Support Services, Oslo University Hospital, Oslo, Norway. ${ }^{3}$ Institute of Medical Psychology and Medical Sociology, University Medical Centre Göttingen, Göttingen, Germany.

Received: 7 July 2016 Accepted: 13 January 2017

Published online: 19 January 2017

\section{References}

1. Ponsford J, Draper K, Schonberger M. Functional outcome 10 years after traumatic brain injury: its relationship with demographic, injury severity, and cognitive and emotional status. J Int Neuropsychol Soc. 2008;14(2):233-42.

2. Safaz I, Alaca R, Yasar E, Tok F, Yilmaz B. Medical complications, physical function and communication skills in patients with traumatic brain injury: a single centre 5-year experience. Brain Inj. 2008;22(10):733-9.

3. Nampiaparampil DE. Prevalence of chronic pain after traumatic brain injury: a systematic review. JAMA. 2008;300(6):711-9.

4. Dikmen SS, Machamer JE, Powell JM, Temkin NR. Outcome 3 to 5 years after moderate to severe traumatic brain injury. Arch Phys Med Rehabil. 2003;84(10):1449-57.

5. Draper K, Ponsford J, Schonberger M. Psychosocial and emotional outcomes 10 years following traumatic brain injury. J Head Trauma Rehabil. 2007;22(5):278-87.

6. Andelic N, Sigurdardottir S, Schanke AK, Sandvik L, Sveen U, Roe C. Disability, physical health and mental health 1 year after traumatic brain injury. Disabil Rehabil. 2010;32(13):1122-31.

7. Andelic N, Hammergren N, Bautz-Holter E, Sveen U, Brunborg C, Roe C. Functional outcome and health-related quality of life 10 years after moderateto-severe traumatic brain injury. Acta Neurol Scand. 2009;120(1):16-23.

8. Andelic N, Perrin PB, Forslund MV, Soberg HL, Sigurdardottir S, Sveen U, et al. Trajectories of physical health in the first 5 years after traumatic brain injury. J Neurol. 2015;262(3):523-31.

9. WHO. International classification of functioning, disability and health. Geneva: World Health Organization; 2001. 
10. von Steinbuechel N, Petersen C, Bullinger M. Assessment of health-related quality of life in persons after traumatic brain injury - development of the Qolibri, a specific measure. Acta Neurochir Suppl. 2005;93:43-9.

11. Von Steinbuchel N, Wilson L, Gibbons H, Hawthorne G, Hofer S, Schmidt S, et al. Quality of Life after Brain Injury (QOLIBRI): scale development and metric properties. J Neurotrauma. 2010;27(7):1167-85.

12. Novack TA, Bush BA, Meythaler JM, Canupp K. Outcome after traumatic brain injury: pathway analysis of contributions from premorbid, injury severity, and recovery variables. Arch Phys Med Rehabil. 2001;82(3):300-5.

13. Renner C, Hummelsheim H, Kopczak A, Steube D, Schneider HJ, Schneider $M$, et al. The influence of gender on the injury severity, course and outcome of traumatic brain injury. Brain Inj. 2012;26(11):1360-71.

14. Sigurdardottir S, Andelic N, Roe C, Schanke AK. Cognitive recovery and predictors of functional outcome 1 year after traumatic brain injury. J Int Neuropsychol Soc. 2009;15(5):740-50.

15. Sigurdardottir S, Andelic N, Roe C, Jerstad T, Schanke AK. Post-concussion symptoms after traumatic brain injury at 3 and 12 months post-injury: a prospective study. Brain Inj. 2009;23(6):489-97.

16. WHO. The World Health Organization Quality of Life Assessment (WHOQOL): development and general psychometric properties. Soc Sci Med. 1998:46(12):1569-85.

17. Corrigan JD, Bogner J. Latent factors in measures of rehabilitation outcomes after traumatic brain injury. J Head Trauma Rehabil. 2004;19(6):445-58.

18. Dijkers MP. Quality of life after traumatic brain injury: a review of research approaches and findings. Arch Phys Med Rehabil. 2004;85(4 Suppl 2):S21-35.

19. Bullinger M, Azouvi P, Brooks N, Basso A, Christensen AL, Gobiet W, et al. Quality of life in patients with traumatic brain injury-basic issues, assessment and recommendations. Restor Neurol Neurosci. 2002;20(3-4):111-24.

20. Guyatt GH, Veldhuyzen Van Zanten SJ, Feeny DH, Patrick DL. Measuring quality of life in clinical trials: a taxonomy and review. CMAJ. 1989;140(12):1441-8.

21. Von Steinbuchel N, Wilson L, Gibbons H, Hawthorne G, Hofer S, Schmidt S, et al. Quality of Life after Brain Injury (QOLIBRI): scale validity and correlates of quality of life. J Neurotrauma. 2010;27(7):1157-65.

22. Truelle JL, Koskinen S, Hawthorne G, Sarajuuri J, Formisano R, Von Wild K, et al. Quality of life after traumatic brain injury: the clinical use of the QOLIBRI, a novel disease-specific instrument. Brain Inj. 2010;24(11):1272-91.

23. Beaton DE, Bombardier C, Guillemin F, Bosi M. Guidelines for the process of cross-cultural adaption og self-report measures. SPINE. 2000;25(24):3186-91.

24. Anke A, Andelic N, Skandsen T, Knoph R, Ader T, Manskow U, et al. Functional Recovery and Life Satisfaction in the First Year After Severe Traumatic Brain Injury: A Prospective Multicenter Study of a Norwegian National Cohort. J Head Trauma Rehabil. 2015;30(4):E38-49.

25. Hawthorne G, Kaye AH, Gruen R, Houseman D, Bauer I. Traumatic brain injury and quality of life: initial Australian validation of the QOLIBRI. J Clin Neurosci. 2011;18(2):197-202.

26. King NS, Crawford S, Wenden FJ, Moss NE, Wade DT. The Rivermead Post Concussion Symptoms Questionnaire: a measure of symptoms commonly experienced after head injury and its reliability. J Neurol. 1995;242(9):587-92.

27. Zigmond AS, Snaith RP. The hospital anxiety and depression scale. Acta Psychiatr Scand. 1983;67(6):361-70.

28. Schonberger M, Ponsford J. The factor structure of the Hospital Anxiety and Depression Scale in individuals with traumatic brain injury. Psychiatry Res. 2010;179(3):342-9.

29. Wilson JT, Pettigrew LE, Teasdale GM. Structured interviews for the Glasgow Outcome Scale and the extended Glasgow Outcome Scale: guidelines for their use. J Neurotrauma. 1998;15(8):573-85.

30. Pettigrew LE, Wilson JT, Teasdale GM. Reliability of ratings on the Glasgow Outcome Scales from in-person and telephone structured interviews. J Head Trauma Rehabil. 2003;18(3):252-8.

31. Teasdale $G$, Jennett B. Assessment of coma and impaired consciousness. A practical scale. Lancet. 1974;2(7872):81-4.

32. Association for the Advancement of Automotive medicine. The Abbreviated Injury Scale (AIS) 2005 - Update 2008. AAAM.org; 2008.

33. Ulleval Trauma Registry. Oslo University Hospital. 2013.

34. Bland JM, Altman DG. Cronbach's alpha. BMJ. 1997;314(7080):572.

35. Tennant A, Conaghan PG. The Rasch measurement model in rheumatology: what is it and why use it? When should it be applied, and what should one look for in a Rasch paper? Arthritis Rheum. 2007;57(8):1358-62.

36. Tennant A, McKenna SP, Hagell P. Application of Rasch analysis in the development and application of quality of life instruments. Value Health. 2004;7 Suppl 1:S22-6.
37. Hu L, Bentler PM. Cutoff criteria for fit indexes in covariance structure analysis: conventional criteria versus new alternatives. Struct Equ Model Multidiscip J. 1999;6(1):1-55.

38. Koskinen S, Hokkinen EM, Wilson L, Sarajuuri J, VonSteinbuchel N, Truelle JL. Comparison of subjective and objective assessments of outcome after traumatic brain injury using the International Classification of Functioning, Disability and Health (ICF). Disabil Rehabil. 2011;33(25-26):2464-78.

39. Siponkoski ST, Wilson L, Von SN, Sarajuuri J, Koskinen S. Quality of life after traumatic brain injury: Finnish experience of the QOLIBRI in residential rehabilitation. J Rehabil Med. 2013;45(8):835-42.

40. Sasse N, Gibbons H, Wilson L, Martinez-Olivera R, Schmidt H, Hasselhorn M, et al. Self-awareness and health-related quality of life after traumatic brain injury. J Head Trauma Rehabil. 2013;28(6):464-72.

41. Evans CC, Sherer M, Nick TG, Nakase-Richardson R, Yablon SA. Early impaired self-awareness, depression, and subjective well-being following traumatic brain injury. J Head Trauma Rehabil. 2005;20(6):488-500.

42. Svendsen HA, Teasdale TW. The influence of neuropsychological rehabilitation on symptomatology and quality of life following brain injury: a controlled long-term follow-up. Brain Inj. 2006;20(12):1295-306.

43. Prigatano GP, Ogano M, Amakusa B. A cross-cultural study on impaired selfawareness in Japanese patients with brain dysfunction. Neuropsychiatry Neuropsychol Behav Neurol. 1997;10(2):135-43.

44. Grauwmeijer E, Heijenbrok-Kal MH, Ribbers GM. Health-related quality of life 3 years after moderate to severe traumatic brain injury: a prospective cohort study. Arch Phys Med Rehabil. 2014;95(7):1268-76.

45. Forslund MV, Roe C, Sigurdardottir S, Andelic N. Predicting health-related quality of life 2 years after moderate-to-severe traumatic brain injury. Acta Neurol Scand. 2013;128(4):220-7.

46. Finger RP, Fenwick E, Pesudovs K, Marella M, Lamoureux EL, Holz FG. Rasch analysis reveals problems with multiplicative scoring in the macular disease quality of life questionnaire. Ophthalmology. 2012;119(11):2351-7.

47. Pallant JF, Tennant A. An introduction to the Rasch measurement model: an example using the Hospital Anxiety and Depression Scale (HADS). Br J Clin Psychol. 2007;46(Pt 1):1-18

48. Smith Jr EV. Detecting and evaluating the impact of multidimensionality using item fit statistics and principal component analysis of residuals. J Appl Meas. 2002;3(2):205-31.

49. Tennant A. Measuring outcome. Br Med Bull. 2000;56(2):287-95.

50. Ponsford J, Willmott C, Rothwell A, Cameron P, Kelly AM, Nelms R, et al. Factors influencing outcome following mild traumatic brain injury in adults. J Int Neuropsychol Soc. 2000;6(5):568-79.

\section{Submit your next manuscript to BioMed Central and we will help you at every step:}

- We accept pre-submission inquiries

- Our selector tool helps you to find the most relevant journal

- We provide round the clock customer support

- Convenient online submission

- Thorough peer review

- Inclusion in PubMed and all major indexing services

- Maximum visibility for your research

Submit your manuscript at www.biomedcentral.com/submit 